\title{
تأثير منهاجين تدريبيين مقترحين باستخدام زمن دوام الحمل والتكرار في عدد من المتغيرات البدنية والحركية والمهارية للاعبي الكرة الطائرة

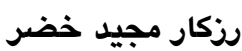

سكول التربية الرياضية، جامعة كويه، اقليم كردستان - العراق.

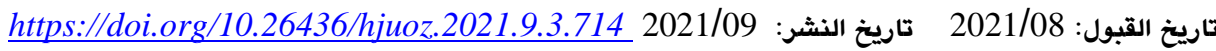

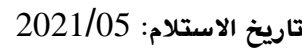

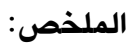

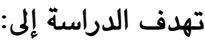

- - الكشف عن تأثير المنهاج التدريبي باستخدام اسلوب التحكم بزمن دوام الحمل في بعض المتغيرات (البدنية والحركية والمهارية) للاعبي الكرة الطائرة الشباب.

- - الكشف عن تأثير المنهاج التدريبي باستخدام اسلوب التحكم بعدد التكرارات في بعض المتغيرات (البدنية والحركية والمهارية) للاعبي الكرة الطائرة الشباب.

- - الكشف عن تأثير المنهاج التدريبي باستخدام اسلوب التحكم بزمن دوام الحمل والتكرار في بعض المتغيرات (البدنية والصركية والمهارية) للاعبي الكرة الطائرة الشباب في الاختبارات والبعدية. اختير مجتمع البحث بطريقة عمدية والمتمثلة بلاعبي الكرة الطائرة فئة الشباب من نادي كوي الرياضي في محافظة اربيل في الكرة الطائرة للموسم الرياضي (2019 - 2020)، أما عينة البحث فقد اختيرت بطريقة عمدية أذ يمثلون (71,42٪) من مجتمع البحث البالغ (28) لاعبا، وقسمت مذه العينة على مجموعتين تجريبيتين بواقع (10) لاعبين لكل مجموعة عن طريق إجراء القرعة، وتم استبعاد 8 لاعبين وذلك لمشاركتهن في التجربة الاستطلاعية والمصابين والتخلف عن التدريب، وكان المنهج المستخدم هو المنهج التجريبي، واستخدم عدد من الادوات والوسائل لجمع البيانات ويعد الحصول على النتائج نوقشت بأسلوب علمي مدعوم بالمصادر لتحقيق اهداف البحث، وفي ضوء نتائج البحث توصل الباحث الى الاستنتاجات الآتية: - - أن أسلوب التحكم بزمن دوام الحمل كان له التأثير الايجابي في المتغيرات البدنية والحركية. - - أن أسلوب التحكم بزمن دوام الحمل كان له التأثير الايجابي في المتغيرات المهارية قيد البحث. - أن أسلوب التحكم بتكرار الحمل كان له التأثير الايجابي في المتغيرات البدنية والحركية. - - أن أسلوب التحكم بتكرار الحمل كان له التأثير الايجابي في المتغيرات المهارية قيد البحث. - على الرغم من التطور الايجابي لمجموعتي البحث التجريبيتين في الاختبارات البعدية إلا انه لم تكن هناك تفوق معنوي لأي الاسلوبين التدريبيين في الاختبارات البعدية. - الكلمات الدالة: زمن دوام الحمل ، زمن دوام التكرار ، منهاجين تدريبيين ، الكرة الطائرة.

تضمنته أ سس و قواعد و طرائق وأ ساليب التدريب الحديثة المعتمدة

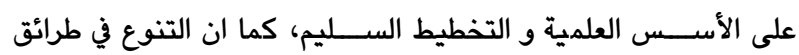
التدريب ووسائل التدريب الحديثة ساعدت المدرب في الارتقاء بالعملية التدريبة لتحقيق افضـــلـ النتائج من خلال تطور المســـتوي البدني والمهاري والخططي والنفسـي للاعبين، ولعبة الكرة الطائرة هي احدى

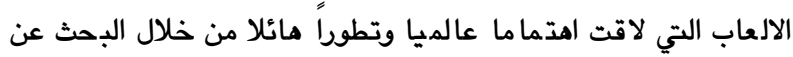

\section{1. التعريف بالبحث}

1-1 المقدمة وأهمية البحث: إن التطور السـريع في تحقيق المســـويات الرياضـية العالية في شـــى المجالات الرياضــة سـواء في الألعاب الجماعية أو الفردية يسـير مواكبا مع التقدم الحاصـــل في علم التدريب الرياضـــي، والارتقاء بهذهـ المستويات لم يأتي من فراغ بل كان وأصبح ومازال العلم هو الأساس، ومن ثم كا نت الجهود مســتمرة نحو مزيد من الفهم والتطبيق لما 
المطلوب حيث أن معظم المناهج التدريبية وعلى الرغم من اسـتخدامها لطرائق واسـاليب تدريبية مختلفة إلا أن طريقة العمل فيها واحدة وهي اخذ المستوى المتوسـط للاعبين جميعاً والعمل بموجبه دون مراعات الفرقق الفردية لهم. وان استخدام اسلوبين تدريبيين بديلة من خلال تنفيذ تمارين بدنية في التدريب لتطوير بعض عناصــــر اللياقة البدنية والحركية والمهارية من

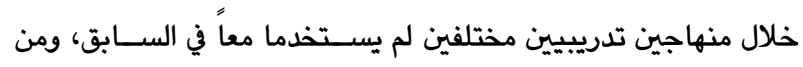

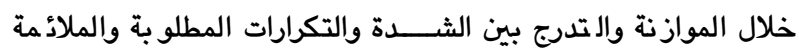
للفعالية من أمكانية الرياضـيـين وقابليتهم خلال وضـــع منهج وتمارين لتدريب بعض اللاعبين الشـــباب لملاحظة أي من المنهاجين يؤثر على بعض عناصـــر اللياقة البدنية والحركية والمهارية لدى لاعبي الكرة

الطائرة.

ومن هنا اتجه تفكير الباحث الى هذه المشكلة في كيفية تطوير عناصر اللياقة البدنية والحركية والمهارية مع مراعات الفروق الفردية من خلال اســــدام منهاجين تدريبيين احدمما يتحكم بزمن دوام الحمل والآخر

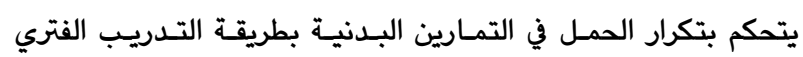
كطريقة تدريبية وا ستخدام التكرار الاقصى للتكرارات من خلال بطاقة المســتوى الخاصـــة بكل لاعب واثر ذلك في عدد من المتغيرات البدنية والحركية والمهارية، وان ما سـبق ذكره دعا الباحث إلى تجريب مذين

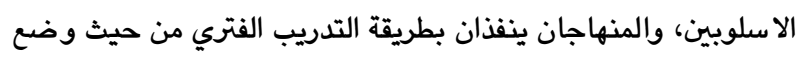
الشدد وعدد التكرارات والازمنة والراحة المناسبة لكل منهاج. ولذلك تتحدد مشكلة البحث في الإجابة عن التساؤلات الآتية: - مل أن تطوير بعض المتغيرات(البدنية والحركية والمهارية) يتم عن طريق استخدام اسلوب التحكم بزمن دوام الحمل أم عن طريق التحكم

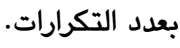
- ما الفرق بين المنهاجين التدريبيين في بعض المتغيرات (البدنية والحركية والمهارية) للاعبي الكرة الطائرة الشباب.

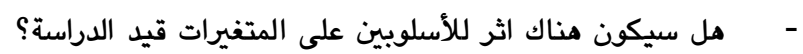
وأي الاسلويين سيكون الافضل؟. 1-3 - - 1 أهداف البحث: يهدف البحث إلى ما يأتي: 1-3-1 الكشف عن تأثير المنهاج التدريبي باستخدام اسلوب التحكم بزمن دوام الحمل في بعض المتغيرات (البدنية والحركية والمهارية) للاعبي الكرة الطائرة الشباب. 1-3-2 الكشف عن تأثي المنهاج التدريبي باستخدام اسلوب التحكم بعدد التكرارات في بعض المتغيرات (البدنية والحركية والمهارية) للاعبي

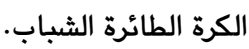
1-3-3 الكشف عن تأثير المنهاج التدريبي باستخدام اسلوب التحكم بزمن دوام الحمل والتكرار في بعض المتغيرات (البدنية والصركية والمهارية) للاعبي الكرة الطائرة الشباب في الاختبارات والبعدية.
الطرق واســاليب اللعب الحديثة في عملية التدريب، وهي لعبة لا تتســم بالاحتكاك وتمارس في ملعب (9 × 18 م) إلا انها مليئة بالإثارة وثـد الجمهود والمشــاهد والمتابع لحركة انتقال الكرة الســريعة بلمســاتها الثلاثة والتي تتميز لخاصــية عدم التملك فالفريق لا يمتلك الكرة لفترة طويلة مثلها مثل باقي العاب الكرة الجماعية الاخرى. فتعـد الكرة الطـائرة من اللعبـات التي تحتــاج إلى الجـانبين البـدني والمهاري وهما جانبان يكونان باســــمرار بحاجة ماســــة إلى اللياقة البدنية لعموم أجزاء الجسـم مما يعطي أهمية خاصـــة لهذه المكونات للاعبي مذه اللعبة، إذ يحتاج اللاعب إلى قوة الرجلين في القفز الســريع كما يحتاج إلى قوة الذراعين في الكبس القوي والصد كما أنه يحتاج إلى إلى قوة الجذع لمواجهة ما يتعرض له من تغيرات في اللعب، والتدريب في الكرة الطائرة يجب أن يينى على أسس علمية رصـينة وحديثة هدفها تدريب اللاعبين باستخدام الوسائل الخاصة والمتاحة للوصول إلى حالة التدريب القصوى لكل لاعب والوصول بهم إلى أعلى المستويات البدنية والحركية والمهارية والخططية لكي يتم تحقيق الاهداف التي يصـــبوا الي ها، والجا نب البدني والحركي والمهاري للاعبي الكرة الطائرة له له اممية كبيرة إذ يتم تطويره بالاعتماد على طرائق واســـاليب تدريبية مختلفة، وأن انسـب طريقة من هذه الطرائق مي طريقة التدريب الفتري

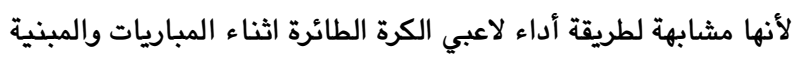

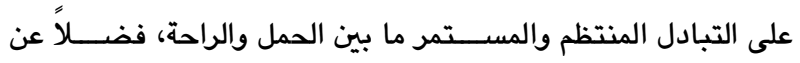
الا سلوب الدائري الذي يعد من افضل الا ساليب المستخدمة في تطوير الجانبين البدني والمهاري في هذه اللعبة لما يوفره للمدرب من الوقت والجهد اثناء التدريب من خلال الاعتماد على الاختبار الاقصــى في التمارين البدنية والحركية باســـتخدام بطاقة المســـوى لكل لاعب منفردا، ولعدم العمل بهذه البطاقة (بطاقة المســتوى) في المناهج التدريبية للعبة الكرة الطائرة تم اســــخدامها لتطوير الجانب البدني والحركي من خلال التحكم بحجم الدمل، ومن هـنا اكتســــب البحث امميته في اســتخدام منهاجين تدريبيين مقترحين للتحكم بحجم الحمل باسـتخدام اسـلويين مختلفين الاول من خلال التحكم بزمن دوام الحمل والثاني من خلال التحكم بتكرار الدمل في التمارين البدنية والحركية واثر ذلك في عدد من المتغيرات البدذية والحركية والمهارية للاعبي الشباب للكرة الطائرة.

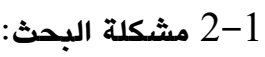
أن التطور العلمي الكبير الذي شـــهدته مختلف الألعاب الرياضــية وخاصـــة الكرة الطائرة يعود إلى اســــفادة العاملين في مجال التدريب الريا ضي من إتباع الأسلوب العلمي الصحيح والتدريب الجيد من اجل

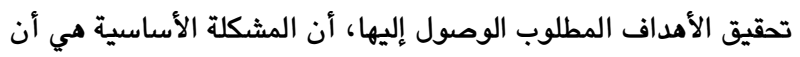
التدريب الرياضـي في إقليم كوردسـتان والعراق مازالت تعاني من ثبات في تطوير النتائج والوصــــل إلى أفضـــل المســــويات مقارنة بالدول

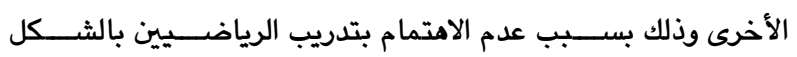




$$
\text { 3-1-1 إجراءات البحث: }
$$

أُستخدم المنهج التجريبي لملاءمته مع طبيعة البحث.

$$
\text { 3-2-3 مجتمع البحث وعينته: }
$$

حُدد مجتمع البحث بطريقة عمدية من لاعبي شباب نادي كويه الرياضي

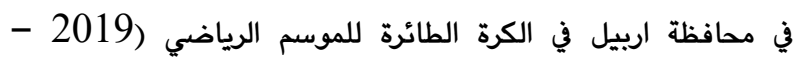
. 2020 واختيرت عينة البحث من هذا المجتمع بشكل عمدي وقوامها (2020) لاعباً

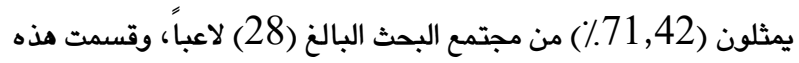

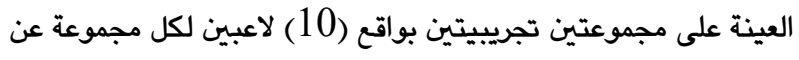
طريق إجراء القرعة. واختير ايضاً (4) لاعبين من مجتمع البحث لإجراء التجارب الاستطلاعية

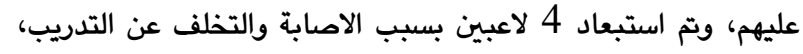

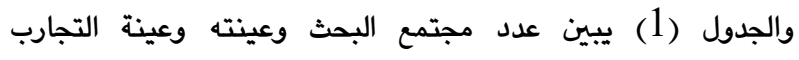
الاستطلاعية فضلاً عن نسبهم المئوية.

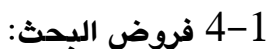

1-4-1 يؤثر المنهاج التدريبي باستخدام اسلوب التحكم بزمن دوام الحمل إيجابياً في بعض المتفيرات (البدنية والحركية والمهارية) للاعبي الترني

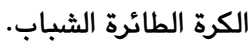

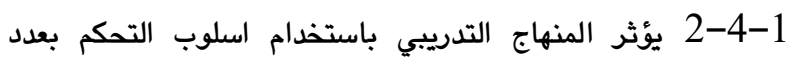
التكرارات إيجابياً في بعض المتغيرات (البدنية والحركية والمهارية)

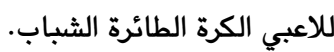
1-3-4 لا توجد فرقق في بعض المتغيرات (البدنية والحركية والمهارية) بين المنهاجين التدريبين باستخدام اسلوب التحكم بزمن

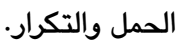

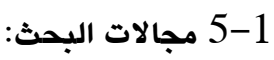
-1 - 1-1-1 المجال البشري: لاعبي نادي كويه الشباب بالكرة الطائرة تحت سن (19) سنة للموسم الرياضي (2019 - 2020).

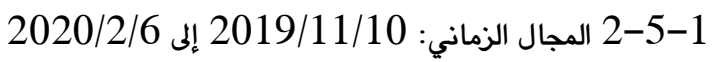

\begin{tabular}{|c|c|c|}
\hline النسبة المئوية & 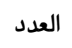 & \\
\hline$\% 100$ & 28 & مجتمع البحث \\
\hline$\% 71,42$ & 20 & عينة البحث \\
\hline$\% 14.28$ & 4 & عينة التجارب الاستطلاعية \\
\hline$\% 14.28$ & 4 & المصابين والمتخلفين عن التدريب \\
\hline
\end{tabular}
1-5-3-5 المجال المكاني: القاعة المغلقة لنادي كويه الرياضي.

الجدول (1) المعلومات المتعلقة بعدد مجتمع البحث وعينته وعينة التجارب الاستطلاعية ونسبهم المئوية

باستخراج قيمة (ت) المحسوية والاحتمالية، والجدول (2) يبين المعتمدة

3-3 تجانس مجموعتي البحث والتكافؤ بينهما: أُجري التجانس والتكافؤ لمجموعتي البحث في متغيرات (العمر والطول في التجانس.

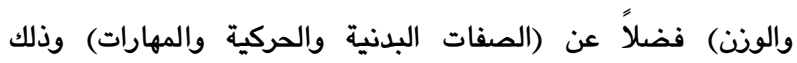

\begin{tabular}{|c|c|c|c|c|c|c|c|c|}
\hline \multirow{2}{*}{ الاحتمالية } & \multirow{2}{*}{ قيمة (ت) } & \multicolumn{2}{|c|}{ 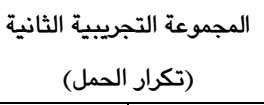 } & \multicolumn{2}{|c|}{$\begin{array}{c}\text { المجموعة التجريبية الأولى (زمن دوام الحمل) } \\
\text { الحمل }\end{array}$} & \multirow{2}{*}{ القياس } & \multirow{2}{*}{\multicolumn{2}{|c|}{ المتغيرات }} \\
\hline & & $\varepsilon^{ \pm}$ & س- & $\varepsilon^{ \pm}$ & س- & & & \\
\hline 0.496 & 0.709 & 4.32 & 16.50 & 3.03 & 16.80 & سنة & العمر & \multirow{3}{*}{ المتغيرات } \\
\hline 0.242 & 1.253 & 5.02 & 174.80 & 1.08 & 176.60 & سم & الطول & \\
\hline 0.366 & 0.951 & 4.27 & 59.30 & 3.48 & 61.20 & كفم & الوزن & \\
\hline 0.643 & 0.911 & 6.25 & 42.70 & 6.14 & 41.00 & سم & القوة الانفجارية للرجلين & \multirow{3}{*}{ البدنية المتغات } \\
\hline 0.991 & 0.528 & 1.44 & 9.10 & 1.87 & 8.80 & عدد & $\begin{array}{c}\text { القوة المميزة بالسرعة لعضلات } \\
\text { المادة للذراعين }\end{array}$ & \\
\hline 0.714 & 1.003 & 2.11 & 6.60 & 2.48 & 7.20 & سم & مرونة العمود الفقري على المحود & \\
\hline 0.553 & 0.098 & 0.44 & 6.86 & 0.50 & 7.20 & ثانية & الرشاقة & \\
\hline
\end{tabular}
الجدول (2) الأوساط الحسابية والانحرافات المعيارية وقيمة (ت) المحسوية ومستوى الاحتمالية بين مجموعتي البحث في متغيرات (الصفات الجسمية، الصفات البدنية، الصفات الحركية، المهارات) 
خضر، رزكار مجيد / مجلة العلوم الانسانية لجامعة زاخو، مجلد:9 ، العدد:3 ، ص 664- 679 ئيلون- 2021.

\begin{tabular}{|c|c|c|c|c|c|c|c|c|}
\hline 0.222 & 0.583 & 2.63 & 13.40 & 2.07 & 13.90 & درجة & توافق (العين واليد) & الحركية \\
\hline 0.732 & 0.044 & 10.13 & 60.20 & 9.39 & 63.00 & نقاط & دقة الارسال لنقاط صعبة محدده & \multirow{3}{*}{ الههارية } \\
\hline 0.449 & 0.688 & 2.71 & 13.60 & 2.45 & 13.40 & نقاط & دقة الاعداد القريب من الشبكة & \\
\hline 0.656 & 0.276 & 2.71 & 13.60 & 2.45 & 13.40 & نقاط & 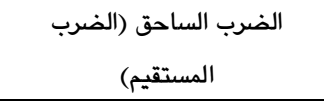 & \\
\hline
\end{tabular}

3-4-4-4 اختبار دقة الارسال للنقاط الصعبة محددة (حسانين

$$
\text { وعبدالمنعم، 1997، 211) }
$$

3-4-4-2 واختبار الاعداد القريب من الشبكة (حسانين وعبدالمنعم،

3-4-4-3 اختبار مهارة الضرب الساحق (الضرب المستقيم) (عبد

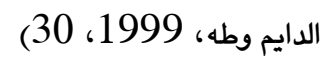

3-5 وسائل جمع المعلومات والبيانات:

3-5-1-3 تحليل المحتوى:

استخدم الباحث تحليل المحتوى للحصول على معلومات دقيقة تخص بثثه، وذلك عن طريق تحليل محتوى المصادر العلمية والدراسات

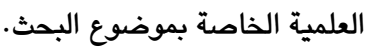
3-5-2-5 الاستبيان:

صميم عدد من الاستبيانات ووزعت على عدد من المتخصصين في تخصصات مختلفة وكانت كما يأتي: استبيان يحتوي على أهم الصفات والاختبارات البدنية والحركية بالكرة الطائرة تم توزيعه على المتخصصين في مجالات علم التدريب الرياضي وفسلجة التدريب الرياضي والقياس والتقويم والكرة الطائرة

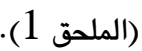

استبيان يحتوي على أهم المهارات واختباراتها في بالكرة الطائرة تم توزيعه على المتخصصين في مجالات القياس والتقويم والكرة الطائرة

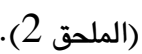

استبيان يحتوي على المنهاجين التدريبيين للتأكد من صلاحيتهما تم توزيعه على المتخصصين في مجالات علم التدريب

الرياضي وفسلجة التدريب الرياضي والكرة الطائرة (الملحق 3). 3-6 التصميم التجريبي المستخدم تم استخدام التصميم التجريبي الذي يطلق عليه تصميم المجموعات

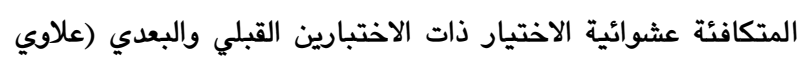

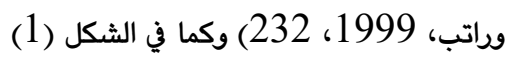

من خلال الجدول (2) يتضح أن قيم (ت) المحسوية كانت على التوالي

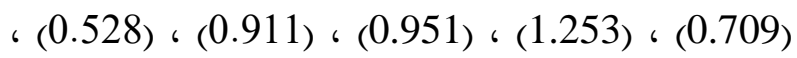
، (0.688) ، (0.044) ، (0.583) ، (00.98) ، (1.003)

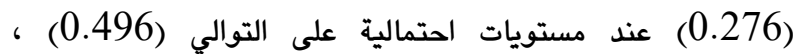
، (0.714) ، (0.991) ، (0.643) ، (0.366) ، (0.242)

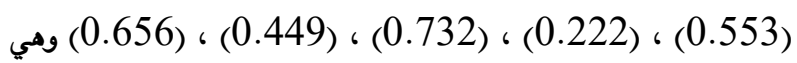
أكبر من (0,05) مما يدل على عدم وجود فروق ذات دلالة معنوية بين

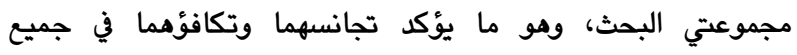
المتغيرات المعتمدة. 3-4 القياسات والاختبارات المستخدمة في البحث: 3-4-1 القياسات الجسمية (قياسا الطول والوزن): تم قياس طول وقنن المختبرين من عينة البحث بجهاز (DETECTO)

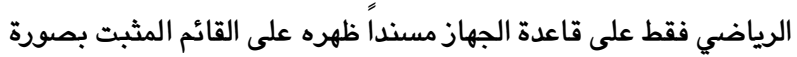

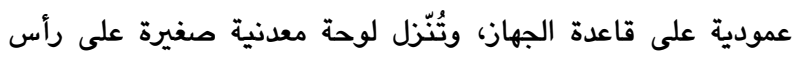
المختبرين من القائم المعدني وهي التي يحدد بموجبها طول المختبر،

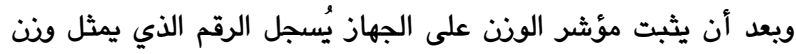
المختبر الحقيقي ويتم القياس لأقرب مئة غرام. 3-4-2-3 الاختبارات البدنية: 3-4-2-1 اختبار الوثب العمودي لسارجنت (علاوي رضوان، (84، 1982 3-4-2-2 اختبار ثني ومد الذراعين ( شناو ) في 10 ثوانٍ للمتقدمين 3-3-3-3-3 اختبار ثني الجذع من الوقوف 3-3-3 الاختبارات الحركية: 3-4-3-1 اختبار الجري الزكزاك بين الحواجز(علاوي رضوان، 1982 3-4-3-2 اختبار رمي واستقبال الكرات

\begin{tabular}{|c|c|c|c|}
\hline (اختبار بعدي) & التدريب باستخدام زمن دوام الحمل & (اختبار قبلي) & المجموعة التجريبية الاولى \\
\hline (اختبار بعدي) & التدريب باستخدام تكرار الحمل & (اختبار قبلي) & المجموعة التجريبية الثانية \\
\hline
\end{tabular}
3-4-4 الاختبارات المهارية: 
من أجل ضمان تحقيق السلامة الخارجية للتصميم التجريبي ينبغي أن تكون تجربة البحث خالية من الأخطاء والمعوقات لكي يتم تعميم نتائج البحث على عينات متشابهة لعينة البحث، فراعى الباحث ذلك بإجراء

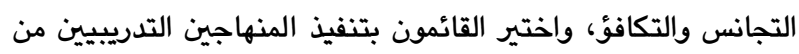

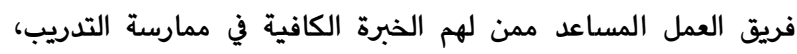
وروعيت المدة المخصصة لتنفيذ تجرية البحث ومكان وموقع التجرية. 3-9 خطوات الإجراءات الميدانية: 3-9-1 تصميم وبناء المنهاجين التدريبيين: تم بناء منهاجان تدريبيان مقترحان لمجموعتي البحث (الملدق 3) وكان الأول يحتوي على التدريب باستخدام زمن دوام الحمل والثاني

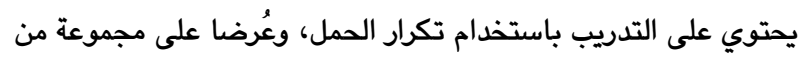
المتخصصين في مجالات التدريب الرياضي وفسلجة التدريب الرياضي والكرة الطائرة لبيان رأيهم في صلاحية المنهاجين المعروضين. 3-9-2-9 التجارب الاستطلاعية: أجرى الباحث تجريتين استطلاعيتين بالاستعانة بفريق العمل المساعد، وكان لكل تجربة أهداف تختلف عن أهداف التجرية الأخرى وذلك كما 3-9-2-1 التجربة الاستطلاعية الأولى على الاختبارات

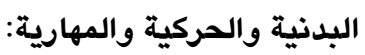
أجريت هذه التجرية في المدة من (2019/11/10) إلى (2019/11/14) على (4) أفراد من مجتمع البحث ويمساعدة فريق العمل المساعد، وأجري اثناءها اختبار (الاختبارات البدنية والحركية والمهارية) المستخدمة في البحث، وكان الهدف من التجربة ما يأتي: التأكد من صلاحية الأدوات والأجهزة المستخدمة. التأكد من ملاءمة الاختبارات والقياسات لمستوى عينة البحث. التأكد من كفاءة فريق العمل المساعد ومدى إتقانه للعمل. التعرف على كافة الصعويات والمعوقات الممكن ظهورما في الاختبارات والقياسات. معرفة المدة الزمنية لأداء كل اختبار وقياس.

3-2-9-2 التجربة الاستطلاعية الثانية على التدريبات

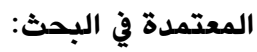

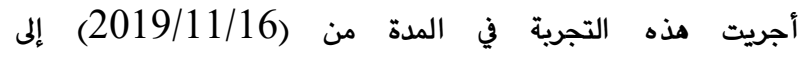
(2019/11/19) على (4) أفراد أيضاً من مجتمع البحث ويمساعدة فريق العمل المساعد واجريت اثناءها تدريبات اختيرت من المنهاجين التدريبيين، وكان الهدف من التجرية ما يأتي: التعرف على الزمن الذي يستغرقه كل نوع من التدريب. تحديد الواجبات المناطة بكل فرد من أفراد فريق العمل المساعد أثناء تنفيذ التدريبات. التعرف على مدد الراحة بين التكرارات وبين المجموعات بواسطة
3-7 تحديد المتغيرات وضبطها: إن من خصائص العمل التجريبي "إزالة تأثير أي متغير (عدا المتغير

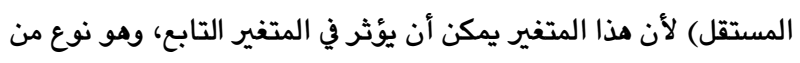
التثبيت أو العزل للمتغيرات التي يرى الباحث أنها قد تؤثر في نتائج

$$
\text { 3-7-1 التجريب" (الشوك والكبيسي، 2004، 62). }
$$

"وهو العامل أو السبب الذي يُطبق لمعرفة أثره في النتيجة" (العساف، المئ المبن 1989، 306) وقد تناول البحث الحالي نوعين من المتغيرات المستقلة

$$
\text { التدريب باستخدام زمن دوام الحمل. }
$$

3-7-2-7 المتغير التابع: هو "العامل الذي ينتج من تأثير المتغير المستقل" (عبيدات وآخران، (281، 1996

وقد تناول البحث الحالي ثلاثة أنواع من المتغيرات التابعة وهي: • المتغيرات البدنية، (القوة الانفجارية للرجلين والقوة المميزة بالسرعة لعضلات المادة للذراعين ومرونة العمود الفقري على المحور الأفقي). • المتغيرات الحركية، وهي (اختبار الجري الزكزاك بين الحواجز واختبار رمي واستقبال الكرات). • المتغيرات المهارية، وهي (اختبار دقة الارسال للنقاط الصعبة واختبار الاعداد القريب من الشبكة واختبار مهارة الضرب الساحق (الضرب المستقيم). 3-7-3 المتغيرات غير التجريبية (الدخيلة): ينبغي تصديد هذه المتغيرات والسيطرة عليها، فهي قد تؤثر بطريقة أو بأخرى في سلامة المتغير التابع، ويعد ضبط المتغيرات الدخيلة واحداً من الإجراءات المهمة في البحث التجريبي لتوفير درجة مقبولة من صدق التصميم التجريبي". (عودة ومكاوي، 1987، 3-8 السلامة الداخلية والخارجية للتصميم التجريبي: 3-8-1-8 السلامة الداخلية: ثم التحقق من السلامة الداخلية للتصميم التجريبي، فقد تمت السيطرة على المتغيرات التي تؤثر في المتغير التابع وهي: التباين في اختبار وتوزيع أفراد عينة البحث: ومصدر هذا العامل هو عدم التكافؤ بين مجموعتي البحث. أدوات القياس المستخدمة في البحث: تمت السيطرة على هذا العامل باستخدام أدوات موحدة لمجموعتي البحث. ظروف التجربة والعوامل المصاحبة لها: مثل النضج والنمو وعدم إهدار الوقت بالتزام اللاعبين في حضور جميع مفردات المنهاجين التدريبيين. 3-8-2 السلامة الخارجية: 
بتمارين تهدئة واسترخاء للعضلات كافة واستغرقت من (5-10) دقائق، أما القسم الرئيسي فتكّون من التدريب المعتمد في البحث.

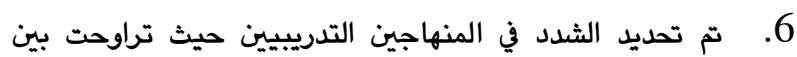
(60\% - 80٪) لمجموعتي البحث في التدريب باستخدام التحكم بزمن دوام الحمل والتدريب باستخدام تكرار الحمل. 3-9-5 الاختبارات والقياسات البعدية: بعد الانتهاء من تنفيذ المنهاجين التدريبيين للمجموعتين التجريبيتين،

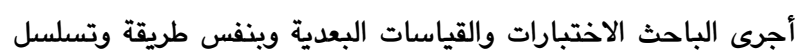
الاختبارات والقياسات القبلية وكما يأتي: في يوم (2020/2/4) أجري الاختبارات البدنية والحركية

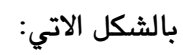

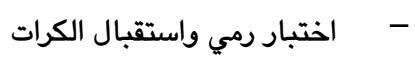
- اختبار ثني ومد الذراعين ( شناو ) في 10 ثوانٍ للمتقدمين

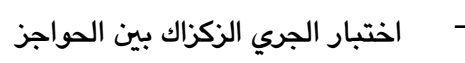

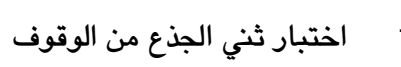

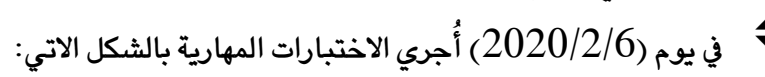

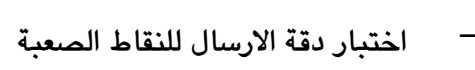

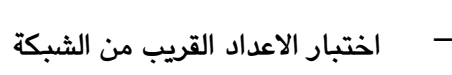

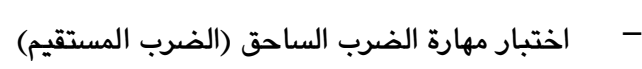

\section{3-10-3 الوسائل الإحصائية:}

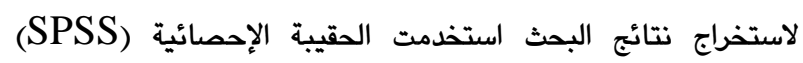

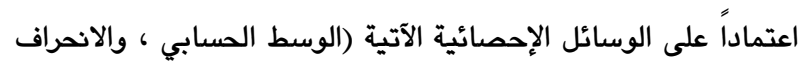

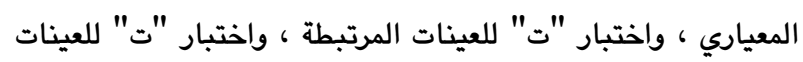

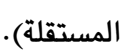

4-1-1 عرض وتحليل النتائج الخاصة بالمتغيرات البدنية والحركية ومناقشتها:

4-1-1-1 عرض والجركية ومناهثيل: النتائج الخاصة بالمتغيرات البدنية

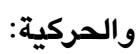

3-9-3 الاختبارات والقياسات القبلية: أُجريت الاختبارات والقياسات القبلية في المدة من (2019/11/23) إلى (2019/11/25) كما يأتي: في يوم (2019/11/23) أُجري الاختبارات البدنية والحركية

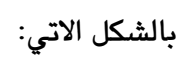

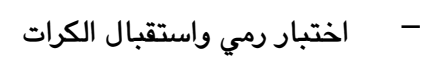
- - متبار الوثب العمودي لسارجنت - - اختبار ثني ومد الذراعين ( شناو ) في 10 ثوانٍ للمتقدمين

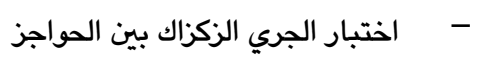

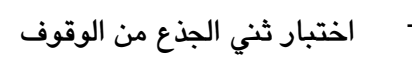
في يوم (2019/11/25) أجري الاختبارات المهارية بالشكل 3-9-4 تنفيذ المنهاجين التدريبيين: تم تنفيذ المنهاجان التدريبيان المقترحان على مجموعتي التهني البحث من تاريخ (2019/11/30) إلى (2020/2/1) وروعيت النقاط الآتية: 1. استخدم المجموعة الاولى منهاج التحكم بزمن دوام الحمل في

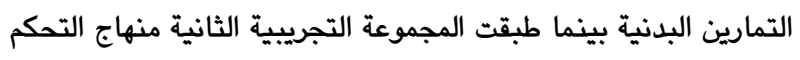

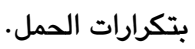
2. تكّون المنهاجان التدريبيان من (3) دورات متوسطة، واحتوت كل دورة متوسطة على (3) دورات صغرى ويتشكيل حمل (2 : 1 1) في كل دورة متوسطة. 3. احتوت كل دورة صغرى على (3) وحدات تدريبية يومية، أي تُفذت في (27) وحدة تدريبية في كل منهاج لمجموعتي البحث.

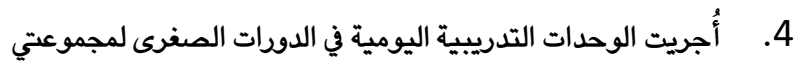
البحث في أيام (السبت ، الأثنين ، الأربعاء).

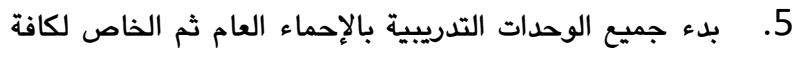
عضلات الجسم العاملة واستغرق 25 دقيقة، وإنهاء الوحدات التدريبية

\begin{tabular}{|c|c|c|c|c|c|c|c|}
\hline \multirow{2}{*}{ الاحتمالية } & \multirow{2}{*}{ قالمسموية (ت) } & \multicolumn{2}{|c|}{ الاختبار البعدي } & \multicolumn{2}{|c|}{ الاختبار القبلي } & \multirow{2}{*}{ وحدة القياس } & \multirow{2}{*}{ المتغيرات } \\
\hline & & $\varepsilon^{ \pm}$ & س- & $\varepsilon^{ \pm}$ & س- & & \\
\hline 0.001 & 21.605 & 5.79 & 64.00 & 6.14 & 41.00 & سم & القوة الانفجارية للرجلين \\
\hline 0.001 & 14.807 & 1.85 & 12.90 & 1.87 & 8.80 & عدد & القوة المميزة بالسرعة لعضلات المادة \\
\hline 0.003 & 10.062 & 2.82 & 10.20 & 2.48 & 7.20 & 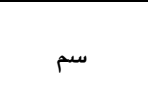 & مرونة العمود الفقري على المحود \\
\hline
\end{tabular}

الجدول (3) الأوساط الحسابية والانحرافات المعيارية في الصفات البدنية والحركية وقيمة (ت) المحسوية ومستوى الاحتمالية بين الاختبارين 


\begin{tabular}{l|l|l|l|l|l|l|l}
\hline 0.002 & 6.309 & 0.41 & 6.59 & 0.50 & 7.20 & ثانية & ثوافق (العين واليد) \\
\hline 0.001 & 4.714 & 1.19 & 16.10 & 2.07 & 13.90 & درجة & داقة \\
\hline
\end{tabular}

\section{* معنوي عند مستوى احتمالية 2 (0,05)}

التدريب بزمن دوام الحمل، ولمصلحة الاختبار البعدي كما هو مبين في من خلال الجدول (3) يتبين وجود فروق ذات دلالة معنوية بين معنماتية

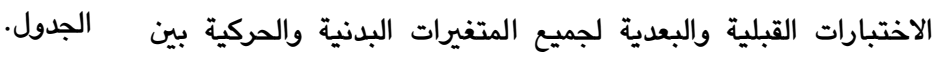
الاختبارين القبلي والبعدي للمجموعة التجريبية الاولى التي استخدم القبليه

الجدول (4) الأوساط الحسابية والانحرافات المعيارية في الصفات البدنية والحركية وقيمة (ت) المحسوية ومستوى الاحتمالية بين الاختبارين القبلي والبعدي للمجموعة الثانية التي استخدم التدريب بتكرار الحمل

\begin{tabular}{|c|c|c|c|c|c|c|c|}
\hline \multirow{2}{*}{ الاحتمالية } & \multirow{2}{*}{ قالمسوبة (ت) } & \multicolumn{2}{|c|}{ الاختبار البعدي } & \multicolumn{2}{|c|}{ الاختبار القبلي } & \multirow{2}{*}{ وحدة القياس } & \multirow{2}{*}{ المتغيرات } \\
\hline & & $\varepsilon^{ \pm}$ & س- ل م- ل & $\varepsilon^{ \pm}$ & س- ل م- ل & & \\
\hline 0.001 & 25.313 & 5.48 & 65.90 & 6.25 & 42.70 & 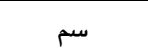 & القوة الانفجارية للرجلين \\
\hline 0.002 & 23.717 & 1.37 & 14.10 & 1.44 & 9.10 & عدد & القوة المميزة بالسرعة لعضلات المادة \\
\hline 0.003 & 10.026 & 2.63 & 9.60 & 2.11 & 6.60 & سم & مرونة العمود الفقري على المحود \\
\hline 0.001 & 5.968 & 0.39 & 6.46 & 0.44 & 6.86 & ثانية & الرشاقة \\
\hline 0.002 & 4.272 & 1.03 & 15.80 & 2.63 & 13.40 & درجة & توافق (العين واليد) \\
\hline
\end{tabular}

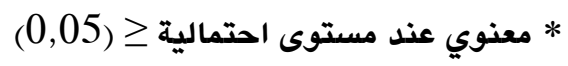

للمنهاجين التدريبيين التي اعتمدت على التخطيط العلمي الدقيق، والذي

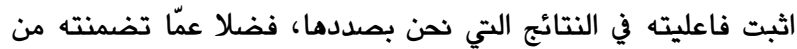
تمارين بدنية محددة بقواعد وشروط علمية معينة مثل عدد او زمن التمان

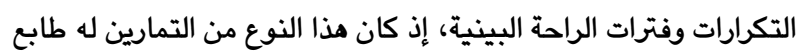

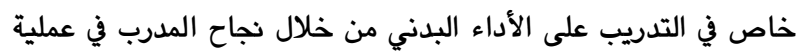
التحكم بحجم الحمل لكلا المجموعتين بأسلوبيه المعتمد على الزمن

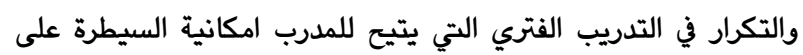
مكونات الحمل حيث أن التدريب الفتري هو عمل أو تمرين تتبعه فترة

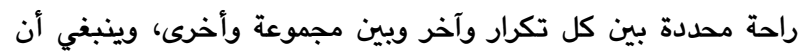

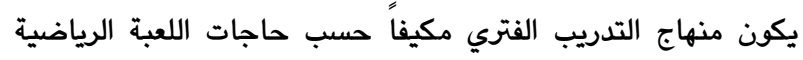
(الحيالي، 2008، 17). أن استخدام طريقة التدريب الفتري التي تميزت بأداء ذات شدد معتدلة ومناسبة تراوحت بين (60 - 80٪) من بداية أول وحدة تدريبية في بادئ

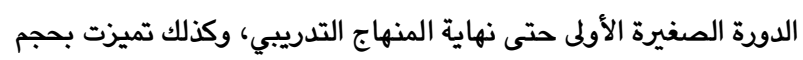

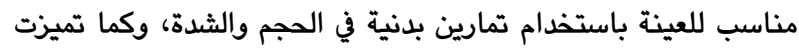

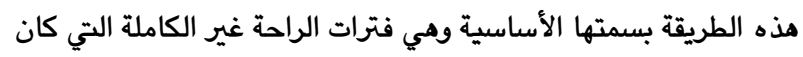

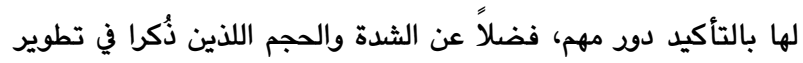
اللياقة البدنية بعامة والقوة الانفجارية والقوة المميزة بالسرعة والمرونة التي تناولها البحث بخاصة، اذ يزداد مستوى تراكم اللاكتات في الدم الدام التارية

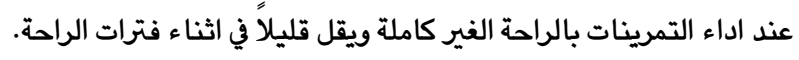

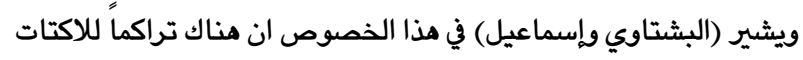
في العضلات والدم اثناء العمل العضلي البدني وزياده في الدين
من خلال الجدول (4) يتبين وجود فرقق ذات دلالة معنوية بين

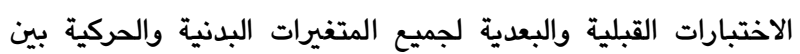
الاختبارين القبلي والبعدي للمجموعة التجريبية التي استخدم التدريب بتكرار الحمل، ولمصلحة الاختبار البعدي كما هو مبين في الجدول. 4-1-2 مناقثة النتائج الخاصة بالمتغيرات البدنية

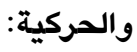
في ضوء النتائج التي تم الحصول عليها من الجداول (3 ، 4 4) التي أظهرت فروقاً معنوية في جميع المتغيرات البدنية (القوة الانفجارية للرجلين والقوة المميزة بالسرعة لعضلات المادة للذراعين ومرونة العمود الفقري على المحور الافقي) والمتغيرات الحركية (الرشاقة وتوافق العين واليد) بين الاختبارين القبلي والبعدي لمجموعتي البحث التجريبيتين

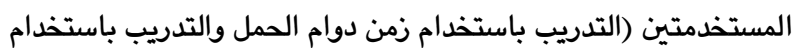
تكرار الحمل)، نرى أن الفرضية الأولى والثانية قد تحققت، اذ أن الباحث دامثل

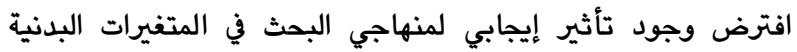

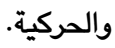

ان هذه النتائج يعزوها الباحث إلى عدة أسباب أهمها ما يأتي:

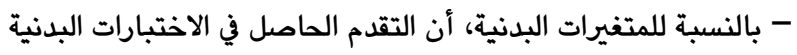
(القوة الانفجارية للرجلين، القوة المميزة بالسرعة لعضلات المادة

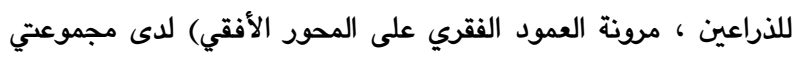

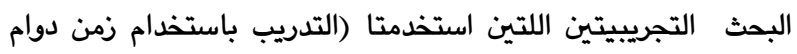
الحمل والتدريب باستخدام تكرار الحمل) الى التأثيرات الايجابية الفعّالة 


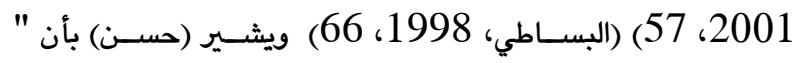

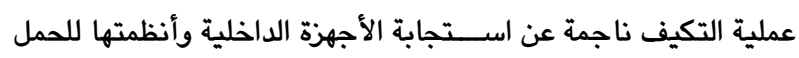
الخارجي ولأي مكون من مكوناته، ومن بين هذه الأنظمة نظام الطاقة الطابه

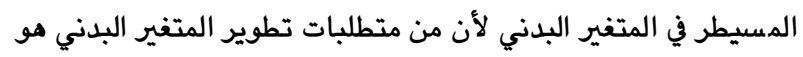

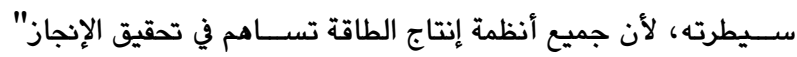
(حسن، 2001، 60). ولابد من الإثارة إلى أن الباحث اعتمد في تدريباته على تمرينات تخدم

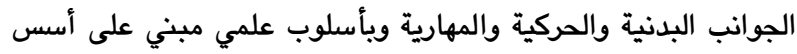

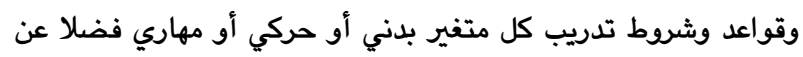

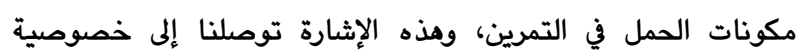
التدريب لنوع التمرين المختار والذي يخدم المتغيرين البدني والمهاري والذي ينعكس على التطور الحاصل في المجاميع العضلية العاملة والمشاركة في الأداء لكل تمرين. ويرى الباحث أيضاً أن من أهم العوامل الفعالة في تطوير المتغيرات

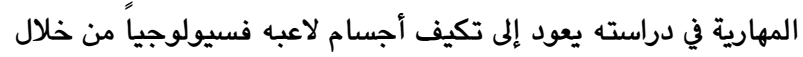
تدريباتهم التي تضمنت تمرينات مبرمجة تميزت عن التمرينات التقليدية

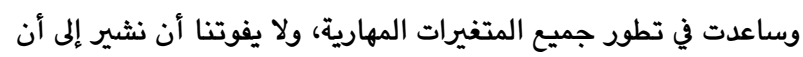
الحمل التدريبي البدني والمهاري والذي استغرق تسعة أسابيع ويصورة منظمة يعد أحد العوامل الرئيسية التي أدت بأجسام اللاعبين إلى حالة

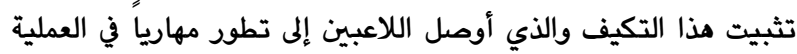

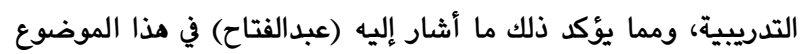
فقد ذكر أنه " من أجل الحصول على تكيفات فسيولوجية حقيقية يجب أن يتم تدريب الرياضي بشكل منظم ومستمر لفترة لا تقل عن (8 -

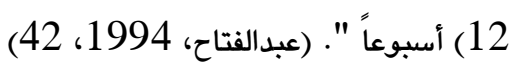
مما سبق استعراضه من نتائج المتغيرات البدنية والمهارية بين الاختبارين القبلي والبعدي نرى أن الفرضين الأول والثاني قد تحققا وهذا ما يؤكد حقيقة أهمية المنهاجين التدريبيين المقترحين من قبل

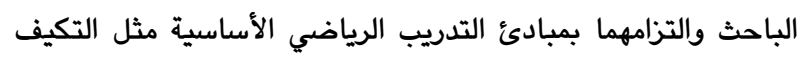
والخصوصية والتدرج بالتدريب والذي انعكس على الجانبين البدني

$$
\text { والمهاري للاعبي الكرة الطائرة في نادي كويه الرياضي. }
$$

4-1-3 عرض وتحليل النتائج الخاصة بالمتغيرات المهارية:

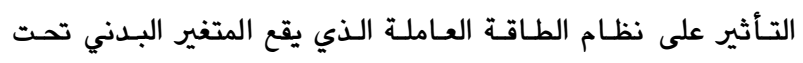

الاوكسجيني الوارد إلى لعضلات وإنخفاضًاً في مستوى تراكم اللاكتات

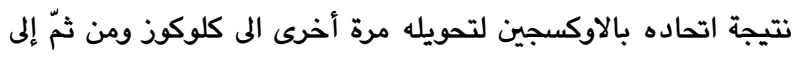

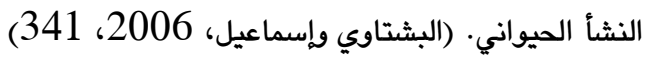
إن الاعتماد على ما سبق ذكره من شروط التدريب الفتري أدى إلى الى

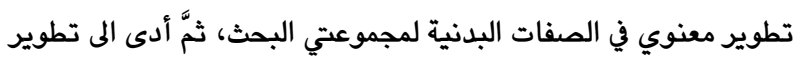

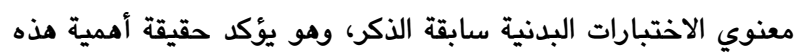
التمارين لتحقيق انجاز افضل. وكذلك التدريب الدائري التي يعمل على تطوير الجانب البدني والمهاري من خلال استخدام عناصر التشويق والاثارة والتحدي اثناء اداء التمرينات حيث ذكر (درويش وحسانين) أنه " غالباً ما يكون هدف التحاري التدريب الدائري هو تنمية الصفات البدنية الاساسية كالقوة والتحمل والسرعة، وعلى وجه الخصوص الصفات ذات الطبيعة المركبة مثل

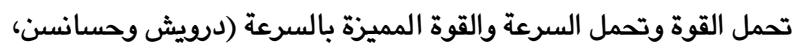
1999، 25) (بحث ادمام)

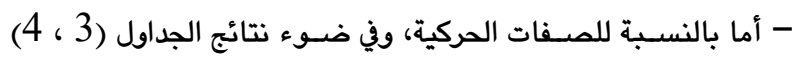

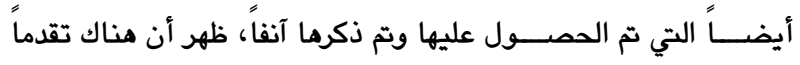

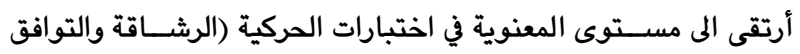

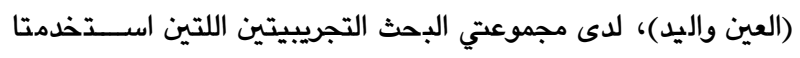
(التدريب باستخدام زمن دوام الحمل والتدريب باستخدام تكرار الحمل) بين الاختبارين القبلي والبعدي ولمملحة الاختبار البعدي،

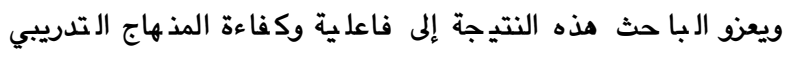

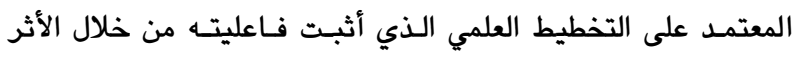

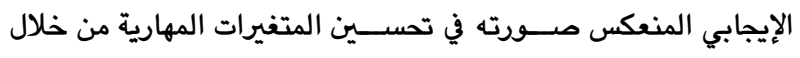

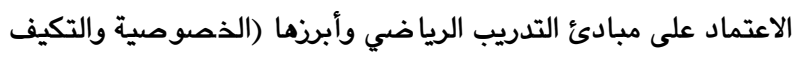

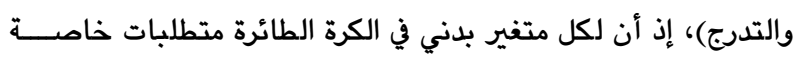

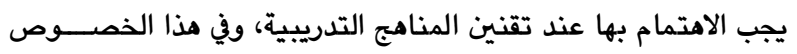
يشير (Macardlc.et.ul) بأن خصوصية التدريب تددث تكيفات

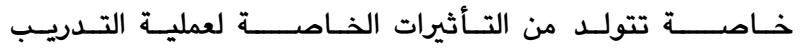
(Macardlc.et.ui, 1981, 28)

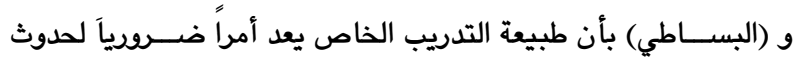

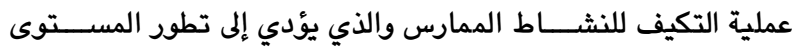

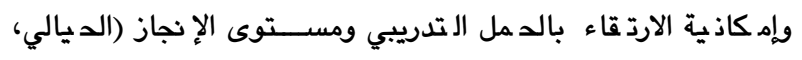
الجدول (5) الأوساط الحسابية والانحرافات المعيارية للمتفيرات المهارية وقيمة (ت) المحسوبة ومستوى الاحتمالية بين الاختبارين القبلي

والبعدي للمجموعة التجريبية الأولى التي استخدم التدريب بزمن دوام الحمل

\begin{tabular}{|c|c|c|c|c|c|c|c|}
\hline \multirow{2}{*}{ الاحتمالية } & \multirow{2}{*}{ قيمة (ت) } & \multicolumn{2}{|c|}{ الاختبار البعدي } & \multicolumn{2}{|c|}{ الاختبار القبلي } & \multirow{2}{*}{ وحدة القياس } & \multirow{2}{*}{ المتغيرات } \\
\hline & & $\varepsilon^{ \pm}$ & 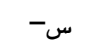 & $\varepsilon^{ \pm}$ & 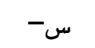 & & \\
\hline 0.002 & 19.000 & 8.94 & 82.00 & 9.39 & 63.00 & نقاط & دقة الارسال لنقاط صعبة محدده \\
\hline 0.000 & 9.498 & 2.01 & 17.60 & 2.45 & 13.40 & نقاط & دقة الاعداد القريب من الشبكة \\
\hline 0.001 & 9.246 & 2.01 & 17.60 & 2.45 & 13.40 & نقاط & الضرب الساحق (الضرب المستقيم) \\
\hline
\end{tabular}

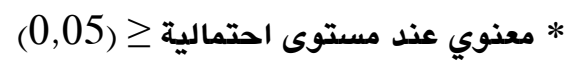


القبلي والبعدي للمجموعة التجريبية التي استخدمت التدريب بزمن دوام

الحمل، ولمصلحة الاختبار البعدي كما هو مبين في الجدول.
من خلال الجدول (5) يتبين وجود فروق ذات دلالة معنوية بين الاختبارات القبلية والبعدية لجميع المتغيرات المهارية بين الاختبارين

الجدول (6) الأوساط الحسابية والانحرافات المعيارية في الصفات المهارية وقيمة (ت) المحسوية ومستوى الاحتمالية بين الاختبارين القبلي والبعدي للمجموعة التجريبية الثانية التي استخدم التدريب بتكرار الحمل

\begin{tabular}{|c|c|c|c|c|c|c|c|}
\hline \multirow{2}{*}{ الاحتمالية } & \multirow{2}{*}{ قيمة (ت) } & \multicolumn{2}{|c|}{ الاختبار البعدي } & \multicolumn{2}{|c|}{ الاختبار القبلي } & \multirow{2}{*}{ وحدة القياس } & \multirow{2}{*}{ المتغيرات } \\
\hline & & $\varepsilon^{ \pm}$ & 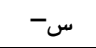 & $\varepsilon^{ \pm}$ & 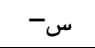 & & \\
\hline 0.000 & 7.828 & 9.90 & 76.20 & 10.13 & 60.20 & نقاط & دقة الارسال لنقاط صعبة محدده \\
\hline 0.001 & 7.415 & 2.32 & 17.50 & 2.71 & 13.60 & نقاط & دقة الاعداد القريب من الشبكة \\
\hline 0.002 & 8.015 & 2.32 & 17.50 & 2.71 & 13.60 & نقاط & الضرب الساحق (الضرب المستقيم) \\
\hline
\end{tabular}

* معنوي عند مستوى احتمالية \ (0,05)

والذراعين لكي يتمكن من الأداء لغرض تحقيق نقطة مباشرة. (الكاتب

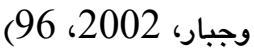

أما فيما يتعلق بدقة الاعداد القريب من الشبكة والنتيجة المعنوية للمجموعتين التجريبيتين تعود الى انعكاس للتمرينات البدنية للبرنامجين التدريبيين المقترحين مما اديا الى تطوير الاداء المهاري للاعبين في الاعداد القريب من الشبكة، حيث أن البرنامج التدريبي الخاص بالتمرينات البدنية أدى الى تطوير الاداء المهاري لمهارة الاعداد القريب من الشبكة للاعبين لان التطور البدني يؤدي الى الاسهام في الاقتصاد في الجهد الذي ييذله اللاعب أثناء الاداء ويالتالي اداء المهارة بشكل متقن وزيادة الكفاءة المهارية من خلال استخدام طرق علمية دقيقة في التدريب، اضافة الى مراعاة الخصائص والفروق الفردية وقدرات اللاعبين والامكانات البشرية والمادية اثناء تصميم البرامج التدريبية، ولاستخدام طرق مختلفة في التدريب بما يخدم الغرض من الدراسة ومذا ما أكده (Magill, 1998) حيث ذكر أن التكرار والتنوع بالتمرينات المنظمة من حيث المدة والتغيير يزيد ويطور الخبرة من قدرة اداء Magill, 1998, ) المهارة بشكل أفضل في مواقع الاختبار الحقيقية 14) وهذا أيضاً اكده (عبد زيد، 2009) حيث اشار على أن الاستعانة بالتمرينات المتنوعة يسهم في ايصال المهارة بشكل متقن (عبد زيد، 2003، 11) ولاحتواء البرنامجين التدريبيين على تمرينات متنوعة في التكرار والزمن وتم تقنينها واعدادها على أسس علمية جيدة تهدف

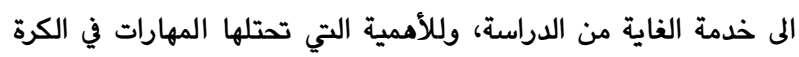
الطائرة ومهارة الاعداد القريب من الشبكة بشكل خاص الأمر الذي دفع الباحث من تناولها ودراستها حيث أنها تتفق مع ما أثار اليه (حماد، 1997) في أن الاعداد هو نقطة الانطلاق لبدء الهجوم ولابد من اتقانها لاستمرار اللعب، وايضاً ذكر (محمد، 2012) أن الاعداد هو أكثر مواقف اللعب حساسية وأهمية حيث يتوقف عليه هجوم الفريق وطريقة

$$
\text { أدائه. (محمد، 2012، مول 369) }
$$

من خلال الجدول (6) يتبين وجود فروق ذات دلالة معنوية بين الاختبارات القبلية والبعدية لجميع المتغيرات المهارية بين الاختبارين القبلي والبعدي للمجموعة التجريبية التي استخدمت التدريب بتكرار الحمل، ولمصلحة الاختبار البعدي كما هو مبين في الجدول.

4-1-4 مناقشة النتائج الخاصة بالمتغيرات المهارية: في ضوء النتائج التي تم الحصول عليها من الجدولين (5 ، 6) التي أظهرت فروقاً معنوية في المتغيرات المهارية المتمثلة في اختبار (دقة الارسال لنقاط محددة ودقة الاعداد القريب من الشبكة والضرب الساحق). بين الاختبارين القبلي والبعدي لمجموعتي البحث التجريبيتين المستخدمتين (التدريب باستخدام بزمن دوام الحمل والتدريب باستخدام تكرار الحمل). ويعزف الباحث هذا التطور إلى كفاءة وفاعلية المنهج التدريبي الذي اعتمد على الركائز العلمية في بنائه مستنداً على المبادئ العامة لعلم التدريب الرياضي والتقنين العلمي الصحيح لمكونات الحمل التدريبي، إذ استطاع الباحث من خلال المنهاج التدريبي المقترح أن يغير بعض التمرينات التقليدية بتمرينات مركبة ذات خصوصية تضفي اليها جانب القوة من خلال التدريب على تمرينات قوة مساعدة خاصة باستخدام الحركات المتقنة والتي ظهر مردودها الإيجابي على الجانبين البدني والمهاري، كما كان التطور الإيجابي للمتغيرات البدنية التي تناولها البحث الأثر الواضح على الجانب المهاري من خلال انتقال أثر تدريب

$$
\text { المتغيرات البدنية والحركية على المتغيرات المهارية. }
$$

فيما يتعلق بمهارة الارسال لنقاط صعبة، تبين وجود علاقة ارتباط معنوية بين بين الاختبارات القبلية والبعدية لمجموعتي البحث في دقة الإرسال لنقاط صعبة لدى عينتي البحث، ويعزف الباحث مذه النتيجة إلى خصوصية هذه المهارة حيث تعتبر من المهارات الحاسمة في الكرة الطائرة ويعتمد بشكل كبير على سرعة الرجلين بالإضافة سرعة الذراع

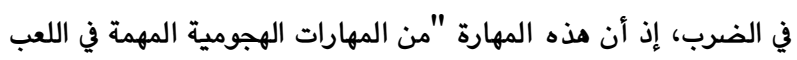
الأمر الذي يتطلب من اللاعب أن يتمتع بشكل القوة الانفجارية للرجلين 
المرجو من الإرسال والضرب الساحق وهو تحقيق نقطة مباشرة ومن ثم الفوز بالشوط والمباراة، إذ أن القوة" قدرة مهمة لجميع المسابقات لكل من الرجال والنساء فالألياف العضلية في العضلات تستجيب عندما تخضع لتأثير ثقل أو مقاومة وهذه الاستجابة تجعل العضلة أكثر قدرة على الاستجابة ويصورة أفضل للجهاز العصبي المركزي (بيترتومسن،

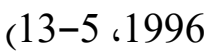

4-1-5 عرض وتحليل النتائج نتائج فروق الاختبارات البدنية والحركية والمهارية البعدية بين اسلوبي التحكم

ومناقشتها.

أما مهارة الضرب الساحق، فيعزو الباحث هذه النتيجة الايجابية لكلا المجموعتين إلى حاجة لاعبي الكرة الطائرة بشكل عام وهذه المهارة بشكل خاص إلى شكل القوة المميزة بالسرعة، إذ أنها مهمة في أثناء التدريب والمباريات، حيث أن طبيعة التمرينات البدنية التي نفذها اللاعبون كان لها الاثر الايجابي لاحتوائها على تمرينات الرقود وتمرينات القفز المتكرد وكذلك الحجل، لان التداخل بين الوثبات والحجلات من اهم الاساليب التي يمكن استخدامها في مجال التدريب الرياضي لتنمية القوة المميزة بالسرعة (Marty, 1988, 150) وهذا ما أدى الي تطوير مهارة الضرب الساحق لان دقة أداء مهارة الضرب الساحق يجب ان يتم على أكمل وجه وفق سرعة كبيرة لكي يتمكن اللاعب من تحقيق الهدف الجدول (7) الأوساط الحسابية والانحرافات المعيارية في الصفات البدنية والحركية للاختبار البعدي وقيمة (ت) المحسوية ومستوى الاحتمالية بين مجموعتي البحث

\begin{tabular}{|c|c|c|c|c|c|c|c|}
\hline \multirow{2}{*}{ الاحتمالية } & \multirow{2}{*}{ قالمحسوية (ت) } & \multicolumn{2}{|c|}{ المجموعة الثانية } & \multicolumn{2}{|c|}{ (زمن دوام الحمل) الأولى } & \multirow{2}{*}{ القياس } & \multirow[t]{2}{*}{ ال المتغيرات } \\
\hline & & $\varepsilon^{ \pm}$ & 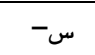 & $\varepsilon^{ \pm}$ & س- & & \\
\hline 0.641 & 0.753 & 5.48 & 65.90 & 5.79 & 64.00 & سم & القوة الانفجارية للرجلين \\
\hline 0.117 & 1.647 & 1.37 & 14.10 & 1.85 & 12.90 & عدد اد & القوة المميزة بالسرعة لعضلات المادة \\
\hline 0.629 & 0.492 & 2.63 & 9.60 & 2.82 & 10.20 & 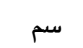 & مرونة العمود الفقري على المحور الأفقي \\
\hline 0.500 & 0.689 & 0.39 & 6.46 & 0.41 & 6.59 & ثانية & الرشاقة \\
\hline 0.556 & 0.600 & 1.03 & 15.80 & 1.19 & 16.10 & درجة & توافق (العين واليد) \\
\hline
\end{tabular}

من الجدول (7) يتبين أنه لا توجد فروق ذات دلالة معنوية في جميع الصفات البدنية والصركية في الاختبار البعدي للمجموعتين التدريبيتين (زمن دوام الحمل) و (تكرار الحمل). الجدول (8) الأوساط الحسابية والانحرافات المعيارية في الصفات المهارية للاختبار البعدي وقيمة (ت) المحسوية ومستوى الاحتمالية بين مجموعتي البحث

\begin{tabular}{|c|c|c|c|c|c|c|c|}
\hline \multirow{2}{*}{ الاحتمالية } & \multirow{2}{*}{ قيمة (ت) } & \multicolumn{2}{|c|}{ المجموعة الثانية } & \multicolumn{2}{|c|}{ (زمن دوام الحمل) } & \multirow{2}{*}{ وحدة القياس } & \multirow[t]{2}{*}{ المتغيرات } \\
\hline & & $\varepsilon^{ \pm}$ & 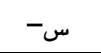 & $\varepsilon^{ \pm}$ & 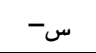 & & \\
\hline 0.186 & 1.374 & 9.90 & 76.20 & 8.94 & 82.00 & نقاط & دقة الارسال لنقاط صعبة محدده \\
\hline 0.919 & 0.103 & 2.32 & 17.50 & 2.01 & 17.60 & نقاط & دقة الاعداد القريب من الشبكة \\
\hline 0.482 & 0.718 & 2.57 & 17.20 & 2.40 & 18.00 & نقاط & الضرب الساحق (الضرب المستقيم) \\
\hline
\end{tabular}

* معنوي عند مستوى احتمالية ج (0.05)

بالزمن واسلوب التحكم بالتكرار، ومو يؤكد التأثير الإيجابي الناتج من

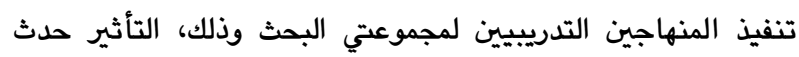
نتيجة التحسن البدني والصركي والمهاري لعينة البحث ولكنه لم تصل الي درجة المعنوية بين مجموعتي البحث التجريبيتين وهذا ما يؤكد أن المنهاجين كانا متماثلين في الاداء واثرا بشكل متناسق على عينتي

5-1-5 الاستنتاجات:

في ضوء النتائج التي تم الحصول عليها استنتج الباحث ما يلي:
من الجدول (8) يتبين أيضاً أنه لا توجد فروق ذات دلالة معنوية في جميع المهارات في الاختبار البعدي للمجموعتين التدريبيتين (زمن دوام الحمل) و (تكرار الحمل).

4-1-5-1-1 مناقشة النتائج الخاصة في الصفات البدينة والحركية والمهارية للاختبارات البعدية لمجموعتي البحث: في ضوء النتائج التي تم الحصول عليها من الجدولين (7 ، 8) ظهر أنه لا توجد فروق معنوية بين مجموعتي البحث التجريبيتين عند المقارنة بين القياسين البعديين لمجموعتي البحث المستخدمتين اسلوب التحكم 
الشوك، نوري إبراهيم و الكبيسي، رافع صالح (2004): دليل البحاث لكتابة

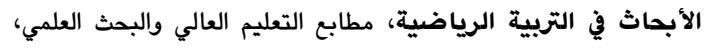

جامعة بغداد، العراق.

العساف، صالح بن محمد (1989): المدخل إلى البحث في العلوم السلوكية، ط10، دار العبيكان للطباعة والنسر، الرياض - المملكة العربية السعودية. حسانين، محمد صبحي، وعبدالمنعم، حمدي (1997): الأسس العلمية للكرة الطائرة وطرق القياس، ط 1، القاهرة، مركز المكتب للنشر.

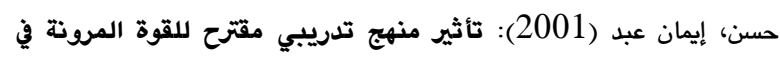
تطوير الأداء الفني لبعض مهارات الجمناستك الإيقاعي، رسالة ماجستير غير منشورة، كلية التربية الرياضية، جامعة بغداد.

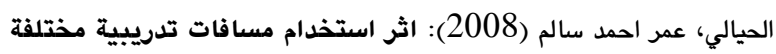

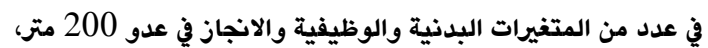
رسالة ماجستير غير منشورة، كلية التربية الرياضية، جامعة الموصل، العراق. الحيالي، معن عبدالكريم جاسم (2001): أثر استخدام تدريبات السرعة بالمساعدة والمقاومة على بعض المتغيرات البدنية والإنجاز

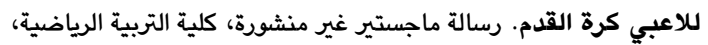

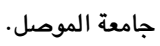
بيترتومسن: (1996)، نظريات التدريب، القاهرة، الاتحاد الدولي لألعاب القوى للهواة.

درويش، كمال، وحسانين، محمد صبحي (1999): الجديد في التدريب الدائري، الطرق والاساليب والنماذج لجميع الالعاب والمستويات الرياضية، مركز الكتاب للنشر، القاهرة، مصر.

عبد الدايم، احمد، وطه، علي مصطفى (1999): دليل المدرب في الكرة الطائرة اختبارات - تخطيط - سجلات، ط1، دار الفكر العربي. عبدالفتاح، أبو العلا أحمد (1994): تدريب السباحة للمستويات العليا. ط1، دار الفكر العربي، القاهرة.

عبد زيد، ناهدة (2003): مفاهيم في التربية الحركية، النجف الاشرف، دار الضياء والتصميم، ط1.

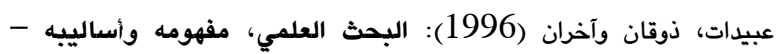
أدواته، دار مجدلاوي للنشر والتوزيع، عمان - الأردن. عودة، احمد سليمان و مكاوي، فتحي حسن (1987): أساسيات البحث العلمي في التربية والعلوم الإنسانية، ط 1، مكتبة المنار للنشر والتوزيع، الزرقاء

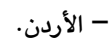

علاوي، محمد حسن، ورضوان، محمد نصرالدين (_1984): اختبارات الأداء الحركي، دار الفكر العربي، القاهرة.

علاوي، محمد حسن، وراتب، أسامة كامل (1999): البحث العلمي في التربية الرياضية وعلم النفس الرياضي، داري، الفكل (لفر العربي، القاهرة - مصر.

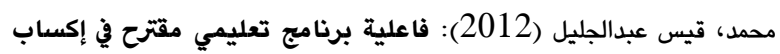

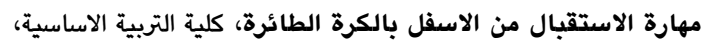

جامعة ديالى، مجلة الفتح، العدد الخمسون.

Macrdle, William D. etal (1981): Exercise Physiology. Energy, Nutrition, and human performance, Lea \& Febiger Co.,.

Magill, A , Richard (1998): motrlearning, Boston McGrwa, (Hi) fifth addiction.
1. أن أسلوب التحكم بزمن دوام الحمل كان له التأثير الايجابي في المتغيرات البدنية والحركية. 2. أن أسلوب التحكم بزمن دوام الحمل كان له التأثير الايجابي في المتغيرات المهارية قيد البحث. 3. أن أسلوب التحكم بتكرار الحمل كان له التأثير الايجابي في المتغيرات البدنية والحركية. 4. أن أسلوب التحكم بتكرار الحمل كان له التأثي الايجابي في المتغيرات المهارية قيد البحث.

5. على الرغم من التطور الايجابي لمجموعتي البحث التجريبيتين إلا انه لم تكن هناك تفوق معنوي لأي الاسلوبين التدريبيين في الاختبارات

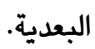
5-2 التوصيات: بعد التعرف على الاستنتاجات العلمية الخاصة بموضوع البحث لابد من وضع عدد من التوصيات لتأكيد مبدأ الاستفادة من هذه الدراسة، لذلك يوصي الباحث بما يأتي: 1. إمكانية استخدام التدريب الفتري بأسلوب التحكم بزمن دوام الحمل وعدم الاكتفاء باستخدام التدريب الفتري بأسلوب التحكم بتكرار الحمل في المتغيرات المتغيرات البدنية والحركية والمهارية 2. الاعتماد على التدريب الفتري بأسلوب الدائري والتحكم بتكرار الحمل وزمن دوام الحمل في بناء المناهج التدريبية لكافة الفعاليات الجماعية وخصوصاً لاعبي الكرة الطائرة.

3. ضرورة الاعتماد على المتغيرات البدنية والحركية لتطوير المهارات في الكرة الطائرة. 4. حث المدربين على ضرورة الاعتماد على كافة الاسس والقواعد التدريبية اللازمة لتصميم ويناء المناهج التدريبية وتشكيل الحمل التدريبي (الشدة والحجم والراحة) وتقنينه للاعبين بشكل سليم. 5. مث المدربين على ضرورة الاعتماد على مبادئ التدريب الرياضي الاساسية في بناء المناهج التدريبية لتأثيرها الايجابي في تحسين الجانب البدني والحركي والمهاري. 6. إجراء بحوث مشابهة على فعاليات جماعية اخرى. 7. إجراء بحوث مشابهة على العنصر النسوي. المصادر

البساطي، أمر الله (1998): قواعد واسس التدريب الرياضي وتطبيقاته. منشأ المعارف، الإسكندرية.

البشتاوي، مهند حسين وإسماعيل، احمد محمود (2006): فسيولوجيا التدريب البدني، ط1، دار وائل للنشر والتوزيع، عمان - الأردن. الكاتب، عقيل وجبار، عامر (2002)، التكتيك والتكتيك الفردي الحديث، بغداد، وزارة التعليم العالي والبحث العلمي. 
التمارين البدنية المستخدمة في البحث:

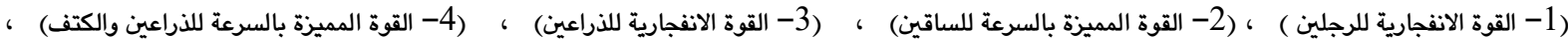

(5- مرونة العمود الفقري والكتفين)

اسلوب التحكم بزمن دوام الحمل

\begin{tabular}{|c|c|c|c|c|c|c|c|c|c|c|c|c|}
\hline الملاحظات & للتمرين الزلي & التمارين & $\begin{array}{c}\text { الراحة } \\
\text { المجاميع }\end{array}$ & المجاميع & $\begin{array}{c}\text { التراحة } \\
\text { التين }\end{array}$ & التكرارات & التمرين اداء & الشدة & البدنية & التدريبية & الصغيرة & المتوسطة \\
\hline \multirow{5}{*}{ الوحدة الثانية } & & 120 ثا & 240 & 3 & 30 ثا & \multirow{5}{*}{ تكرار } & 10 ثا & \multirow{5}{*}{$\% 60$} & تمرين 1 & \multirow{5}{*}{ الأولى } & \multirow{5}{*}{ الأولى } & \multirow{5}{*}{ الأولى } \\
\hline & & 120 ثا & 240 ثا & 3 & 45 ثا & & 15 ثا & & تمرين 2 & & & \\
\hline & & 120 ثا & 240 ثا & 3 & 30 ثا & & 10 ثا & & تمرين 3 & & & \\
\hline & & 120 ثا & 240 ثا & 3 & 45 ثا & & 15 ثا & & تمرين 4 & & & \\
\hline & & 120 ثا & 240 ثا & 3 & 30 ثا & & 10 ثا & & تمرين 5 & & & \\
\hline \multirow{5}{*}{ 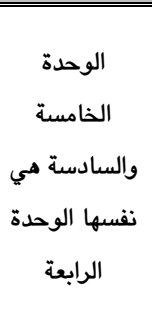 } & & 120 ثا & 240 & 3 & 36 ثا & \multirow{5}{*}{ تكؤ الكرار } & 12 ثا & \multirow{5}{*}{$\% 70$} & تمرين 1 & \multirow{5}{*}{ الرابعة } & \multirow{5}{*}{ الثانية } & \multirow{5}{*}{ الأولى } \\
\hline & & 120 ثا & 240 ثا & 3 & 50 & & 17 ثا & & تمرين 2 & & & \\
\hline & & 120 ثا & 240 ثا & 3 & 36 ثا & & 12 ثا & & تمرين 3 & & & \\
\hline & & 120 ثا & 240 ثا & 3 & 50 & & 17 ثا & & تمرين 4 & & & \\
\hline & & 120 ثا & 240 ثا & 3 & 36 ثان & & 12 ثا & & تمرين 5 & & & \\
\hline \multirow{5}{*}{ والتاسعة هي الثامنة } & & 120 ثا & 240 ثا & 3 & 45 ثا & \multirow{5}{*}{ تلكرار اللاعب } & 15 ثا & \multirow{5}{*}{$\% 80$} & تمرين 1 & \multirow{5}{*}{ السابعة } & \multirow{5}{*}{ الثالثة } & \multirow{5}{*}{ الأولى } \\
\hline & & 120 ثا & 240 ثا & 3 & 60 ثان & & 20 ثا & & تمرين 2 & & & \\
\hline & & 120 ثا & 240 ثا & 3 & 45 ثا & & 15 ثا & & تمرين 3 & & & \\
\hline & & 120 ثا & 240 ثا & 3 & 60 ثان & & 20 ثا & & تمرين 4 & & & \\
\hline & & 120 ثا & 240 ثا & 3 & 45 ثا & & 15 ثا & & تمرين 5 & & & \\
\hline \multicolumn{12}{|c|}{ 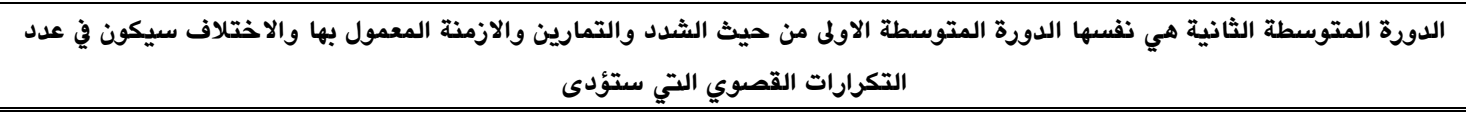 } & الثانية \\
\hline \multicolumn{12}{|c|}{ الدورة المتوسطة الثالثة هي نفسها الدورتين المتوسطتين الاولى والثانية من حيث الشدد والتمارين والازمن المعمول بها والاختلاف } & الثالثة \\
\hline
\end{tabular}
سيكون في عدد التكرارات القصوي التي ستؤدى

\begin{tabular}{|c|c|c|c|c|c|c|c|c|c|c|c|c|}
\hline الملاحظات & اللتمرين & التبن & المبين & المجاميع & التكرارات & التكرارات & التمرين & الشدة & البدنية & التدريبية & الصغيرة & المتوسطة \\
\hline & & 120 ثا & 240 ثا & 3 & 30 & 4 & 10 ثا & \multirow{5}{*}{$\% 60$} & تمرين 1 & \multirow{5}{*}{ الأولى } & \multirow{5}{*}{ الأولى } & \multirow{5}{*}{ الأولى } \\
\hline & & 120 ثا & 240 & 3 & 45 ثا & 8 & 15 ثا & & تمرين 2 & & & \\
\hline & & 120 & 240 & 3 & 30 & 10 & 10 ثا & & تمرين 3 & & & \\
\hline & & 120 ثا & 240 ثا & 3 & 45 نا & 10 & 15 ثا & & تمرين 4 & & & \\
\hline & & 120 ثا & 240 ثا & 3 & 30 & 4 & 10 ثا & & تمرين 5 & & & \\
\hline & & & & & & & & & & & & \\
\hline & & 120 ثا & 240 ثا & 3 & 30 ثا & 4 & 10 ثا & \multirow{3}{*}{$\% 60$} & تمرين 1 & \multirow{3}{*}{ الثانية } & \multirow{3}{*}{ الأولف } & \multirow{3}{*}{ الأولى } \\
\hline & & 120 ثا & 240 ثا & 3 & 45 ثا & 8 & 15 ثا & & تمرين 2 & & & \\
\hline & & 120 ثا & 240 & 3 & 30 & 10 & 10 ثا & & تمرين 3 & & & \\
\hline
\end{tabular}


خضر، رزكار مجيد / مجلة العلوم الانسانية لجامعة زاخو، مجلد:9 ، العدد:3 ، ص 664- 679 ئيلون- 2021.

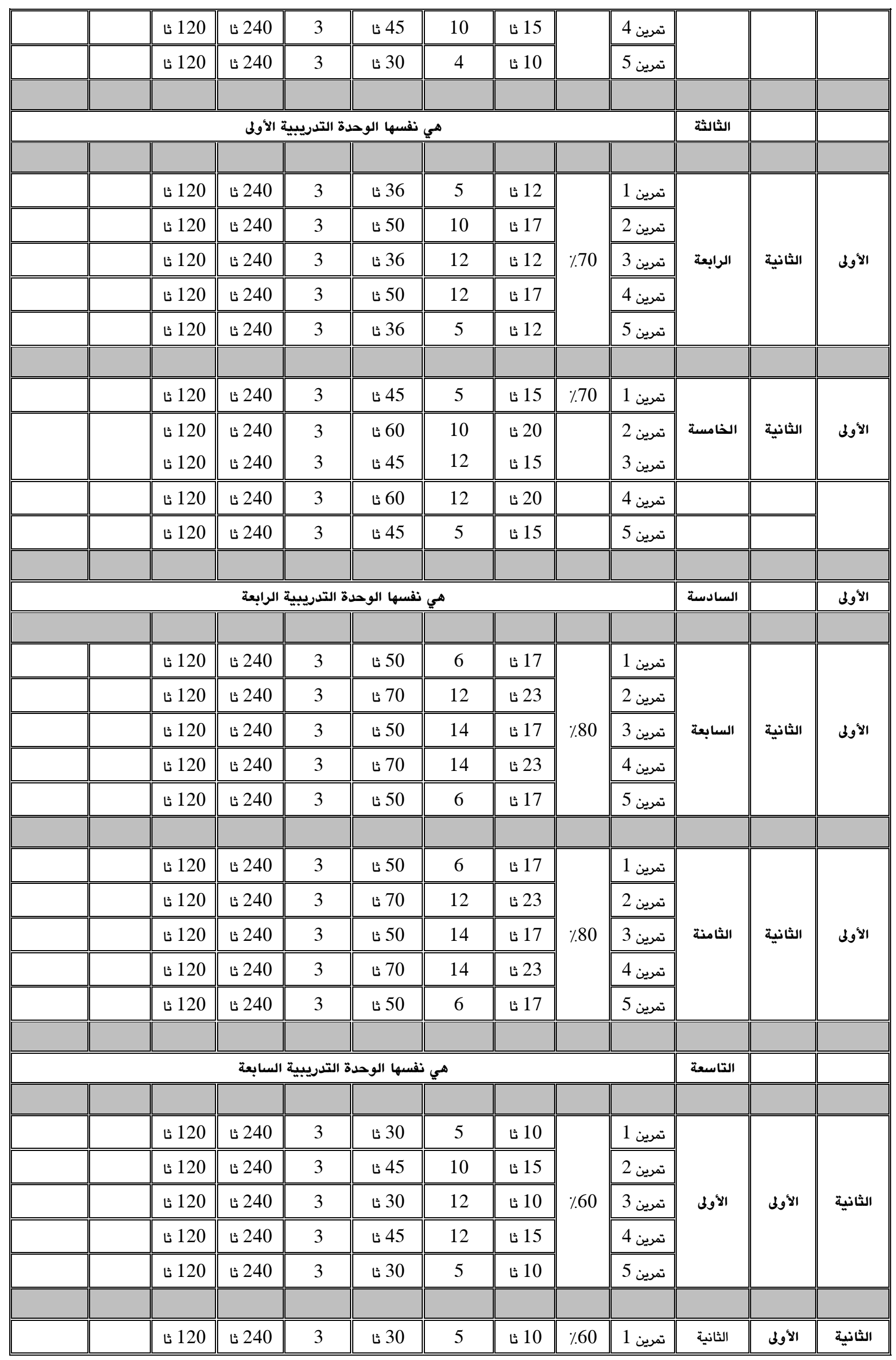


خضر، رزكار مجيد / مجلة العلوم الانسانية لجامعة زاخو، مجلد:9 ، العدد:3 ، ص 664- 679 ئيلون- 2021.

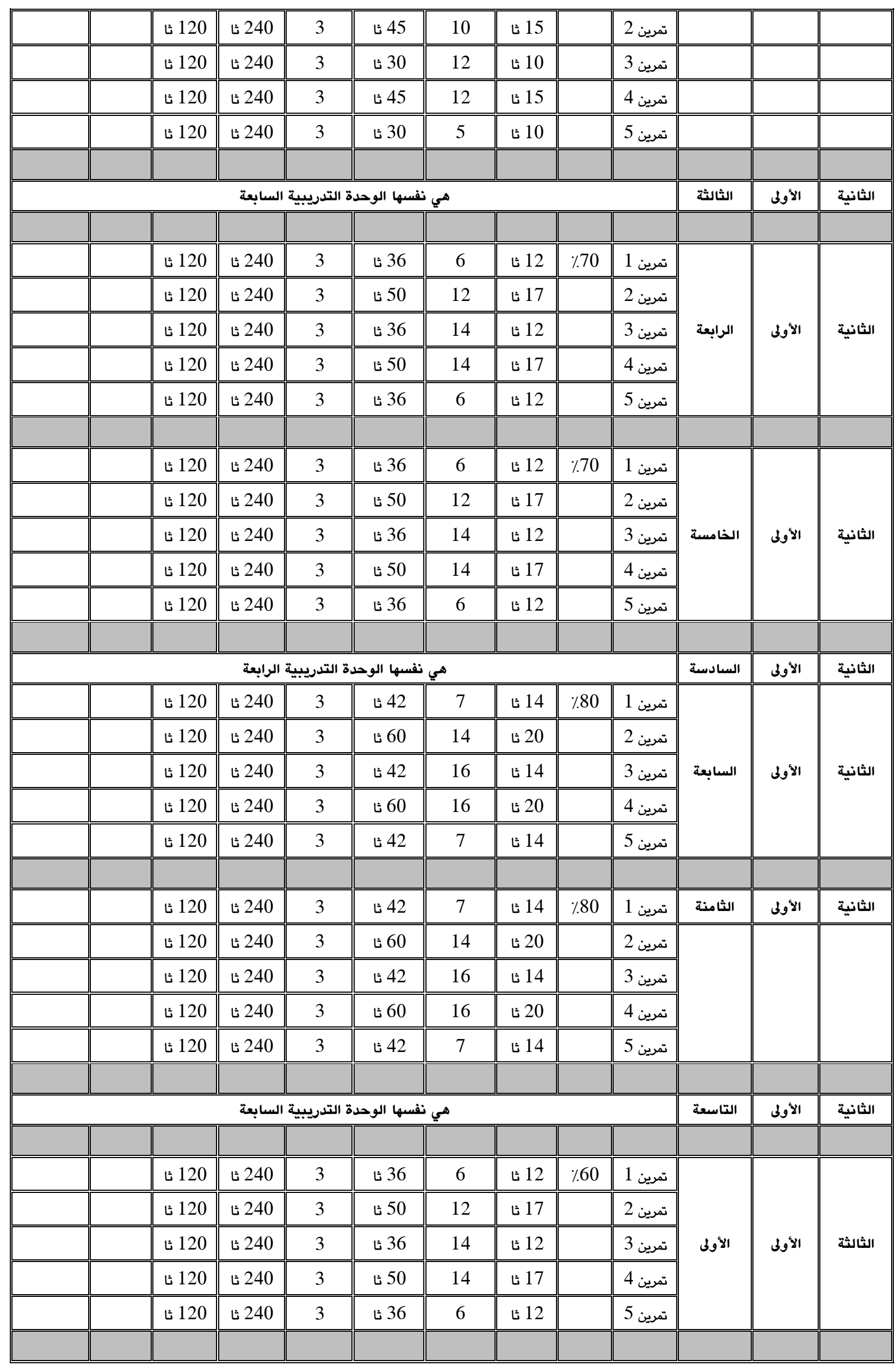


خضر، رزكار مجيد / مجلة العلوم الانسانية لجامعة زاخو، مجلد:9 ، العدد:3 ، ص 664- 679 ئيلون- 2021.

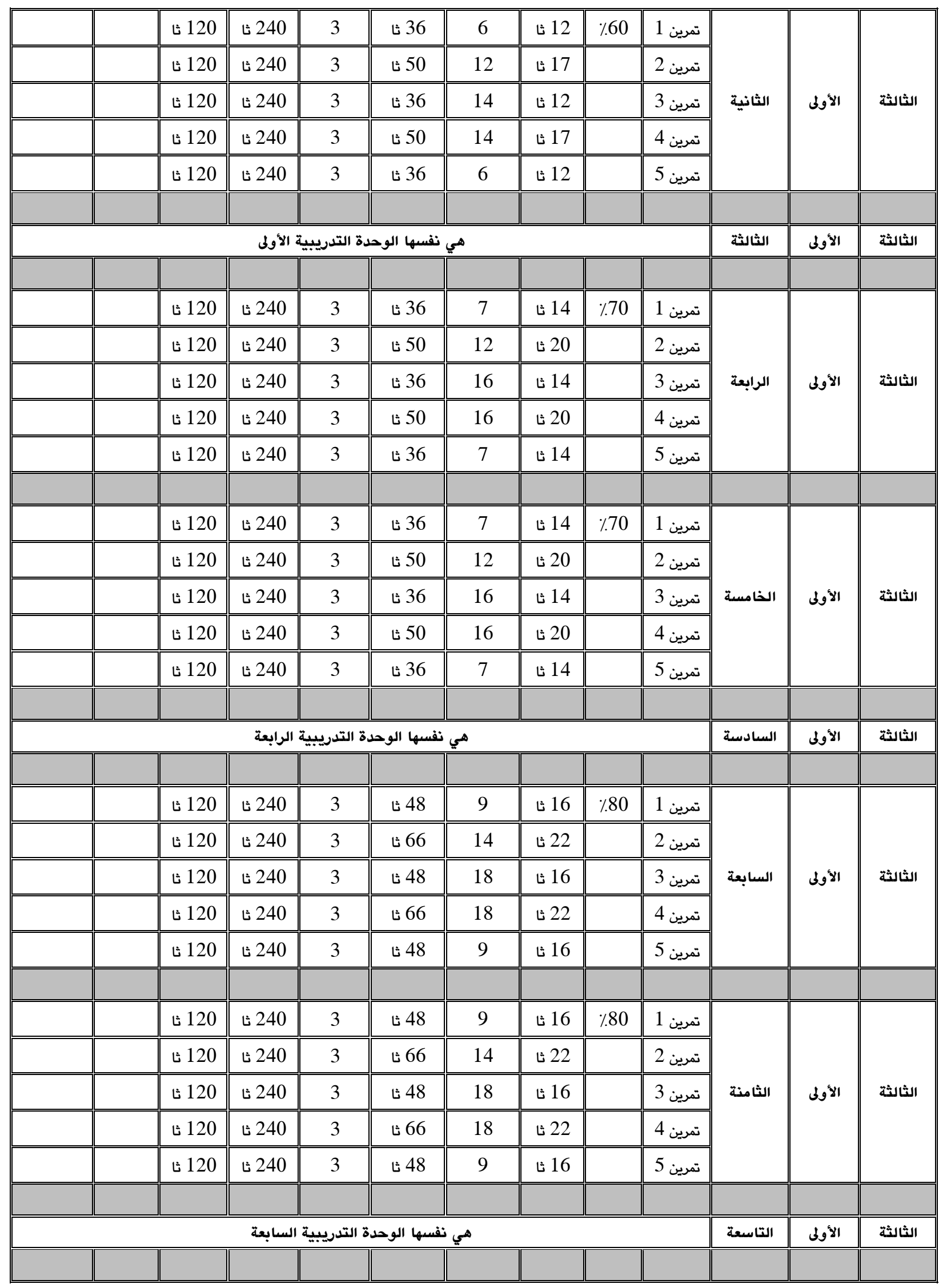


كاريكَهرى دوو يروّكرامى راهيّنانى يِّيشنياركراو بهبهكارهيّنانى كاتى بهردهوامى كارو دوبارهبونهوه لهسهر زمارهيهك كَوْراوى جهستهيى و جولّهيى و

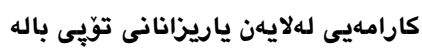

نامانج له م تويَرينهوهيه بريتيه له:

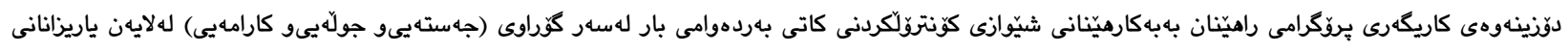
توّيى بالهى لاوان.

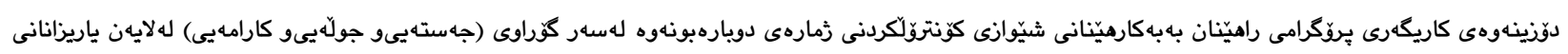
توَيِى بالهى لاوان.

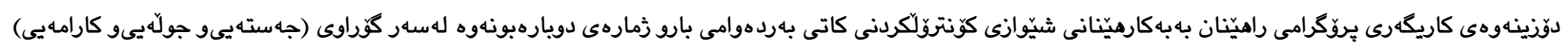

لهلايهن ياريزانانى توّيى بالهى لاوان لهتاقيكردنهوهكانى دوايى.

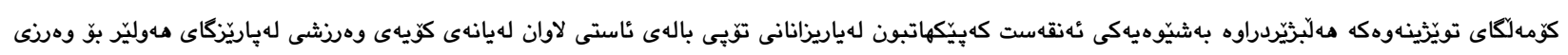

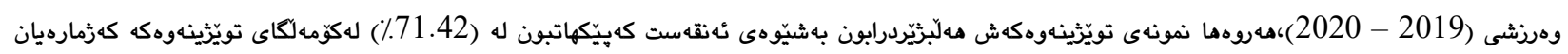

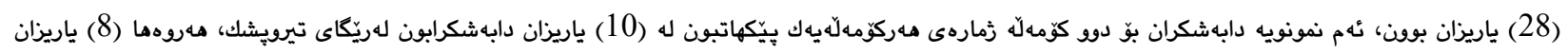

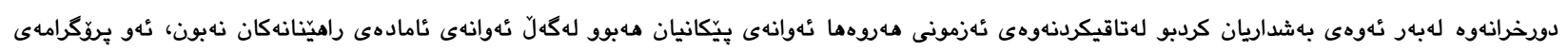

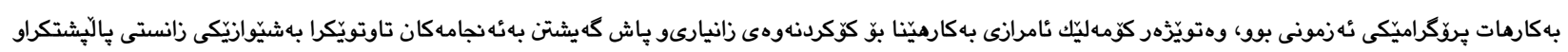

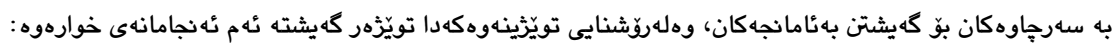

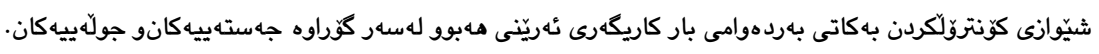

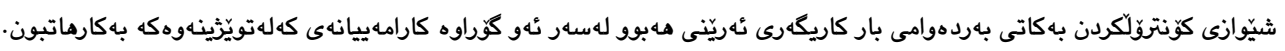

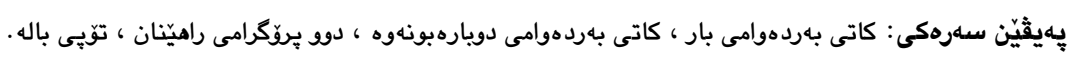

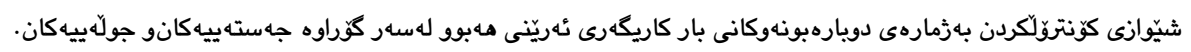

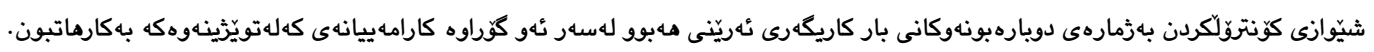

\section{The effect of two proposed training curricula using pregnancy time and repetition on a number of physical, motor and skill variables for volleyball players}

\section{Abstract:}

The study aims to:

- Detecting the effect of the training curriculum using the method of controlling the duration of pregnancy and repetition on some variables (physical, motor and skill) for young volleyball players.

- Detecting the effect of the training curriculum using the method of controlling the number of repetitions in some variables (physical, motor and skill) for young volleyball players.

- Detecting the effect of the training curriculum using the method of controlling the duration of pregnancy on some variables (physical, motor and skill) for young volleyball players.

The research community was chosen in a deliberate way, represented by young volleyball players from Koya Sports Club in Erbil governorate in volleyball for the sports season (2019-2020), As for the research sample, it was chosen in a deliberate way, as they represent $(71.42 \%)$ of the research community of (28) players, and this sample was divided into two experimental groups of (10) players for each group by making a lottery, 8 players were excluded due to their participation in the exploratory experiment, the injured and the failure to train, and the method used was the experimental method, A number of tools and means were used to collect data, and after obtaining the results, they were discussed in a scientific manner supported by the sources to achieve the objectives of the research. In light of the research results, the researcher reached the following conclusions:

- The method of controlling the duration of pregnancy had a positive effect on physical and motor variables.

- The method of controlling the duration of pregnancy had a positive effect on the skill variables under study.

- The method of controlling the recurrence of pregnancy had a positive effect on the physical and motor variables.

- The method of controlling the recurrence of pregnancy had a positive effect on the skill variables under study. Keywords: Pregnancy time, Repetition time, Two training course, Volleyball. 